\title{
Circuit
}

Musiques contemporaines

\section{Un pays à faire : le compositeur Gilles Tremblay a refusé l'Ordre du Canada}

\section{Gilles Tremblay}

Volume 5, numéro 1, 1994

Gilles Tremblay : réflexions

URI : https://id.erudit.org/iderudit/902092ar

DOI : https://doi.org/10.7202/902092ar

Aller au sommaire du numéro

Éditeur(s)

Les Presses de l'Université de Montréal

ISSN

1183-1693 (imprimé)

1488-9692 (numérique)

Découvrir la revue

Citer cet article

Tremblay, G. (1994). Un pays à faire : le compositeur Gilles Tremblay a refusé l’Ordre du Canada. Circuit, 5(1), 59-60. https://doi.org/10.7202/902092ar d'utilisation que vous pouvez consulter en ligne.

https://apropos.erudit.org/fr/usagers/politique-dutilisation/ 


\section{Le compositeur Gilles Tremblay a refusé l'Ordre du Canada}

Paru dans Le Devoir, 5 juin 1982 (copie de la lettre qu'a fait parvenir le compositeur au Gouverneur général du Canada, Monsieur Edward Shreyer).

Il peut arriver que l'on refuse d'accepter un honneur. Je suis amené à le faire vis-à-vis de l'Ordre du Canada. Comme seuls les noms des personnes qui ont accepté sont annoncés officiellement, on pourrait ignorer indéfiniment et les noms et les raisons de ceux qui ont refusé. $I I$ me paraît à la fois sain et souhaitable que le public soit informé. J'ai décidé de le faire après mûre réflexion, sur les conseils de plusieurs amis. Dans un esprit de grande sérénité, voici les termes mêmes de ma lettre au Gouverneur général. 
Le six mai mil-neuf-cent-quatre-vingt-deux, Monsieur Roger de C. Nantel, Directeur de la Chancellerie des Ordres et Décorations du Canada m'annonçait que le Conseil consultatif de l'Ordre du Canada vous recommandait ma nomination à titre d'Officier. A mon grand regret, je ne puis acquiescer à un honneur que dans une situation normale j'aurais accepté avec joie.

Nous sommes en effet dans l'univers des symboles. Mais un symbole n'a de valeur que par le sens qu'il véhicule, et vous savez que tout créateur est lié au monde symbolique. Or, au nom même du sens des mots, de l'acte de choisir, et d'une responsabilité assumée, je me suis prononcé publiquement ces dernières années pour la prise en main du Québec par lui-même. De plus, l'automne dernier le Gouvernement du Canada, à la suite de manœuvres qui ne font honneur à personne, rapatriait la constitution canadienne enchassée d'une nouvelle charte sans la signature du Québec. C'était à toute fin pratique éliminer l'un des peuples fondateurs de ce pays. Ces faits sont bouleversants. Ils demeurent inacceptables même du point de vue d'un fédéralisme véritable, c'est-à-dire respectueux de ses composantes. Peut-on bâtir un pays civilisé et juste sur le mépris?

Vous me répondrez que l'Ordre du Canada se situe au-dessus des partis. J'en suis conscient. II n'en reste pas moins que la Reine du Canada qui est souveraine de l'Ordre et que le Gouverneur général qui en est le Chancelier, représentent l'État, et entérinent la situation actuelle par leurs fonctions mêmes. Faire comme si les symboles n'avaient aucune importance fausse la réalité, distord le SENS.

Dans les circonstances donc, vous comprendrez qu'accepter un tel honneur serait incohérent de ma part. Et, puisqu'il est question d'honneur, mon refus, par son souci de franchise même, s'inscrit paradoxalement dans le respect: à la fois de l'Ordre du Canada, de mes concitoyens, et de moi-même.

C'est dans cette perspective de vérité que je puis, Excellence, vous prier $d^{\prime}$ accepter l'expression sincère de mes sentiments respectueux. 